\title{
Pengaruh Brand Trust terhadap Brand Loyalty Masyarakat dalam Menggunakan Maskapai Batik Air
}

\author{
Devina Dwiastuti Jusuf, Muhammad Gafar Yoedtadi \\ Devinajusuff1997@gmail.com,Gafary@fikom.untar.ac.id
}

Fakultas Ilmu Komunikasi Universitas Tarumanagara

\begin{abstract}
Indonesia has many collections launched by Batik Air.The airline, which is a subsidiary of Lion Air, which is full service, led by Rusdi Kirana, based in Manado, North Sulawesi, has a slogan, Journey Begins. On May 3, 2013 the new Batik Air airline made its maiden flight in the area of Manado.Seiring over time, the airline has a Brand Trust that has an effect on Brand Loyalty, namely community loyalty in the eyes of the public which is quite high. Air Batik which was established in 2013, and in 2017 has been ranked fourth with the most passengers, this flight is seen at 8.4 percent (10,079,902 passengers) of 14 airlines in Indonesia and proves that Brand Trust from the high community influences Brand Loyalty seen from the way people continue to make purchases of airplane tickets.Batik Air as a provider of air transportation services that will continue to strive to improve performance both outside and inside the company Batik Air.
\end{abstract}

Keywords: Batik Air, Brand Loyalty, Brand Trust, Towards Airlines.

\begin{abstract}
Abstrak
Indonesia mempunyai banyak sekali maskapai penerbangan salah satunya adalah maskapai penerbangan Batik Air. Maskapai yang merupakan anak perusahaan dari Lion Air yang berlayanan penuh yang dipimpin oleh Rusdi Kirana yang berbasis di Manado,Sulawesi Utara yang mempunyai slogan yaitu Journey Begins. Pada 3 Mei 2013 maskapai Batik Air baru melakukan penerbangan perdananya di daerah Manado.Seiring dengan berjalannya waktu maskapai ini mempunyai Brand Trust atau Kepercayaan Merek yang berpengaruh terhadap Brand Loyalty yaitu loyalitas masyarakat dimata masyarakat yang terbilang cukup tinggi. Batik Air yang sudah berdiri tahun 2013, dan di tahun 2017 sudah berhasil berada di peringkat ke empat dengan penumpang penerbangan terbanyak ini terlihat sebesar 8,4 persen (10.079.902 penumpang) dari 14 maskapai yang ada di Indonesia dan membuktikan bahwa Brand Trust dari masyarakat yang tinggi berpengaruh terhadap Brand Loyalty terlihat dari cara masyarakat secara terus melakukan pembelian tiket pesawat. Batik Air sebagai penyedia jasa transportasi udara yang akan terus berupaya meningkatkan performa baik diluar maupun didalam perusahaan maskapai Batik Air.
\end{abstract}

Kata Kunci :Batik Air, Brand Loyalty, Brand Trust, Terhadap Maskapai Penerbangan.

\section{Pendahuluan}

Negara Indonesia merupakan negara yang paling besar dan banyak sekali penduduknya, maka dari itu fungsi suatu maskapai penerbangan sangatlah penting untuk mempermudah dan mempercepat perjalanan waktu untuk berpindah-pindah tempat. Penelitian ini akan difokuskan pada maskapai penerbangan Batik Air. Batik Air adalah salah satu dari maskapai penerbangan swasta terbaru Indonesia yang berdiri pada tahun 2013 dengan menggunakan pesawat Boeing 737-900ER. Maskapai 
Batik Air dipimpin oleh Rusdi Kirana yang berbasis di Manado,Sulawesi Utara dengan slogan Journey Begins.

Maskapai ini memang baru saja diluncurkan dan diperkenalkan oleh masyarakat namun dengan hebatnya maskapai ini juga yang paling tepat waktu. Indikatornya persentase ketepatan waktunya berada di angka 88,59 persen. Menurut Sukendro Sukendro dan Pandrianto Aktivasi dalam konteks komunikasi pemasaran adalah menggunakan brand activation. kegiatan mendekatkan brand atau merek dengan penggunanya melalui berbagai aktivitas yang menarik perhatian konsumen. Menurut Lau dan Lee dalam Semadi dan Ariyanti (2018), menjelaskan kepercayaan pada suatu merek atau brand trust adalah sesuai dengan keinginan konsumen dalam mengkonsumsi suatu merek dengan menanggung semua akibatnya baik atau buruknya, namun yang diharapkan tentu yang baik. Menurut Aaker dalam Semadi dan Ariyanti (2018). Brand Loyalty adalah Komitmen konsumen terhadap merek yang telah dibeli dengan cara membelinya dengan pola pembelian yang rutin dan tidak mudah untuk berpaling dari merek lain, jika ia maka akan sulit dan faktor-faktor tertentu saja.

Dalam penelitian ini Teori S-R merupakan proses aksi-reaksi dari suatu kejadian. Stimuli (S) yaitu penangkapan suatu objek lingkungan dengan panca indra contohnya pendengaran dan penglihatan terhadap suatu peristiwa .Sedangkan, response $(\mathrm{R})$ yaitu reaksi yang timbulnya dari stimulus yang berdampak pada sudut pandang, perubahan tingkah laku, dll. Menurut Fisher (dalam Kurniawati 2016:32). Dengan paparan diatas, maka akan dirumuskan masalah yaitu Apakah Brand Trust berpengaruh Brand loyalty penumpang maskapai penerbangan Batik Air? Dan Seberapa besar pengaruh Brand trust terhadap Brand Loyalty penumpang maskapai penerbangan Batik Air? Berdasarkan rumusan masalah diatas maka tujuan dari penelitian ini adalah untuk mengetahui pengaruh Brand Trust terhadap Brand Loyalty penumpang maskapai penerbangan Batik air dan untuk mengetahui besar pengaruh Brand Trust terhadap Brand Loyalty penumpang maskapai penerbangan Batik Air.

\section{Metode Penelitian}

Penelitian ini menggunakan metode kuantitatif menurut Sugiyono (2011), metode kuantitatif yaitu penelitian yang menggunakan SPSS perhitungan statistik dengan menggunakan populasi dan sampel yang sudah ditetapkan. Dalam penelitian ini untuk melihat variabel independen dan variabel dependen saling mempunyai hubungan yang dapat saling mempengaruhi satu sama lain.

"Populasi adalah suatu cakupan wilayah dari suatu orang atau badan tertentu yang sudah ditetapkan oleh peneliti lalu diambil kesimpulannya. menurut Hair et al dalam Prawira (2010) merekomendasikan jumlah sampel minimal adalah 5 kali dari jumlah pertanyaan yang sudah ditetapkan di kuesioner. Dalam penelitian ini terdiri dari variabel independen dan variabel dependen. Total dari pertanyaan dalam penelitian ini adalah 15 indikator yang dijadikan pertanyaan sehingga minimal dalam penarikan sampel penelitian ini adalah 15 pertanyaan x 5 menjadi minimal 75 responden. Metode penarikan sampel yang digunakan dalam penelitian ini adalah metode non-probability sampling dengan pendekatan purposive sampling. Menurut Sugiyono (2015) dengan sampel yang telah ditetapkan dengan Teknik purposive sampling yaitu karena peneliti telah menetapkan semua sampel yang memiliki ciri-ciri sesuai dengan penulis inginkan untuk ditanyakan. kriteria yang dicari oleh peneliti 
yaitu responden yang pernah menggunakan maskapai Batik Air setidaknya 2 kali,responden yang secara frekuentif menggunakan maskapai Batik Air dan responden yang memahami dan mengerti isi dari pernyataan- pernyataan kuesioner dalam penelitian.Variabel yang dilakukan dalam penelitian ini yaitu dibagi menjadi dua yaitu variabel bebas yang dapat mempengaruhi dan menjadi peran penting dalam munculnya variabel terikat. Variabel bebas dalam penelitian ini yaitu Brand Trust dan variabel terikat yaitu Brand Loyalty.

Dalam penelitian ini menggunakan Teknik pengolahan data dan analisis data Tekniknya yaitu regresi sederhana. Pada penelitian ini menggunakan teknik data dengan teknik hitung- menghitung skala likert. Dengan menggunakan Teknik penghitungan data tersebut maka dapat mengukur sikap responden,pendapat responden dan tanggapan seseorang tentang penelitian ini. Dalam penelitian ini juga responden dapat memilih berbagai pilihan sebagai berikut : Sangat Setuju (SS),Setuju (S),Netral (N),Tidak Setuju (TS),Sangat Tidak Setuju (STS). Analisis data yaitu regresi sederhana ada hubungannya dengan satu variabel independen yaitu $\mathrm{X}$ dan variabel dependen yaitu Y. Dalam penelitian ini tujuannya yaitu untuk mengetahui apakah hubungan diantara keduanya naik atau turun dan positive atau negatif. Rumusan datanya regresi sederhana adalah $\mathbf{Y}^{\prime}=\mathbf{a}+\mathbf{b}(\mathbf{X})$ Dengan rumusan tersebut dapat dinyatakan dalam penelitian ini adalah Brand Trust dan Brand Loyalty dari paparan di atas mempunyai indikator-indikatornya dari masing-masing variabel menjadi pertanyaan yaitu :

Tabel 1. Operasional Variabel

\begin{tabular}{|c|c|c|c|c|}
\hline Variabel & Dimensi & Indikator & Butir & Skala \\
\hline \multirow{7}{*}{ Brand Trust } & Brand & 1.Persepsi & BT 1 & \multirow{3}{*}{ Likert } \\
\hline & \multirow[t]{2}{*}{ Characteristic } & 2. Reputasi & BT 2 & \\
\hline & & 3. Kompeten & BT 3 & \\
\hline & Company & $\begin{array}{l}\text { 4. Reputasi suatu } \\
\text { perusahaan }\end{array}$ & BT 4 & \multirow[b]{2}{*}{ Likert } \\
\hline & Characteristic & $\begin{array}{l}\text { 5. Motivasi perusahaan } \\
\text { yang diinginkan }\end{array}$ & BT 5 & \\
\hline & \multicolumn{2}{|r|}{$\begin{array}{l}\text { 6. Kemiripan antara konsep } \\
\text { emosional konsumen } \\
\text { dengan pengalaman } \\
\text { terhadap merek. }\end{array}$} & BT 6 & \multirow[t]{2}{*}{ Likert } \\
\hline & Characteristic & $\begin{array}{l}\text { 7. Hubungan-hubungan } \\
\text { yang bernilai tinggi }\end{array}$ & BT 7 & \\
\hline \multirow{6}{*}{ Brand Loyalty } & $\begin{array}{l}\text { Behavior } \\
\text { Measures }\end{array}$ & $\begin{array}{l}\text { 1.Memperhitungkan } \\
\text { pola pembelian actual }\end{array}$ & BL 1 & Likert \\
\hline & Measuring & 2.Ketidakpuasan pelanggan & BL 2 & \\
\hline & Satisfaction & $\begin{array}{l}\text { 3.Faktor penarik yang } \\
\text { cukup kuat }\end{array}$ & BL 3 & Likert \\
\hline & Measuring & 4.Kehangatan & BL 4 & \multirow{3}{*}{ Likert } \\
\hline & Liking the & 5. Kedekatan & BL 5 & \\
\hline & Brand & $\begin{array}{l}\text { 6.Kemauan untuk membayar } \\
\text { harga yang lebih mahal. }\end{array}$ & BL 6 & \\
\hline
\end{tabular}




\begin{tabular}{llll}
\hline $\begin{array}{l}\text { Measuring } \\
\text { Commitment }\end{array}$ & $\begin{array}{l}\text { 7.Jumlah interaksi } \\
\text { 8.Komitmen pelanggan terkait } \\
\text { dengan produk tersebut. }\end{array}$ & BL 8 & Likert \\
& &
\end{tabular}

Dengan hasil pengukuran data diatas maka skala likert yang telah dilakukan untuk mengukur dari sikap-sikap responden dari pertanyaan yang akan diberikan. Dalam penelitian ini menggunakan analisis deskriptif ,Uji Validitas ,Uji Reliabilitas, Uji Hipotesis dengan menggunakan regresi linier sederhana, Uji T dan korelasi koefisien.

\section{Hasil Temuan dan Diskusi}

Dengan hasil kuesioner yang telah disebarkan kepada penumpang Batik Air yang berada di Bandara Soekarno Hatta, Jakarta, peneliti mendapatkan data-data dari ciri-ciri responden yaitu dari usia responden, jenis kelamin responden, sudah berapa kali naik Batik Air, Alasan naik Batik Air, sebagai berikut:

a. Usia Responden : Terdiri dari yang berusia 21-25 tahun sebanyak 3 orang (3,2\%), 25-30 tahun sebanyak 15 orang (15,6\%), 30-35 tahun sebanyak 28 orang $(29,1 \%), 35-40$ tahun yaitu 40 orang $(42 \%), 40-45$ tahun sebanyak 10 orang $(10,1 \%)$.

b. Jenis Kelamin : Responden yang berdasarkan jenis kelamin yaitu responden jenis kelamin laki-laki sebanyak 56 orang $(58,3 \%)$ dan responden berjenis kelamin perempuan sebanyak 40 orang $(41,7 \%)$.

c. Sudah berapa kali naik Batik Air : Banyaknya responden yang sudah naik 1 kali sebanyak 25 orang (26\%) dan >1 kali sebanyak 71 orang (74\%).

d. Alasan naik Batik Air : Banyaknya responden yang naik Batik air karena pekerjaan terdiri 40 orang $(41,7 \%)$,tamasya sebanyak 31 orang $(32,3 \%)$, urusan keluarga sebanyak 20 orang $(20,8 \%)$, DLL sebanyak 20 orang $(5,2 \%)$.

\section{Uji Validitas}

Uji ini dalam penelitian penulis digunakan supaya menguji instrumen penelitian terhadap 96 Responden yang pernah menaiki Maskapai Batik Air. Pengujian yaitu dengan cara menjadikan 0.1689 Sebagai patokan terhadap tabel Corrected ItemTotal Correlation.Berikut adalah hasil uji validitas dari dimensi (X1) :Brand Trust (X2) : Brand Loyalty (Y) Terhadap Masyarakat Dalam menggunakan Maskapai Batik Air dinyatakan valid seluruhnya karena nilai Corrected Item-Total Correlation lebih besar dari 0.1689

Tabel 2. Hasil Uji Validitas Brand Trust Batik Air

\begin{tabular}{lcc}
\hline \multicolumn{1}{c}{ Pertanyaan } & $\begin{array}{c}\text { Corrected Item- } \\
\text { Total Correlation }\end{array}$ & Keterangan \\
\hline $\begin{array}{l}\text { Saya memiliki persepsi yang baik mengenai } \\
\text { Batik Air }\end{array}$ & .429 & Valid \\
\hline $\begin{array}{l}\text { Saya merasa Batik Air memiliki reputasi } \\
\text { yang dapat dipercaya. }\end{array}$ & .381 & Valid \\
\hline
\end{tabular}


Devina Dwiastuti Jusuf, Muhammad Gafar Yoedtadi: Pengaruh Brand Trust Terhadap Brand Loyalty Masyarakat Dalam Menggunakan Maskapai Batik Air

\begin{tabular}{lcc}
\hline $\begin{array}{l}\text { Saya merasa Batik Air kompeten dalam } \\
\text { melayani penumpang }\end{array}$ & .422 & Valid \\
\hline $\begin{array}{l}\text { Batik Air merupakan maskapai yang } \\
\text { memiliki karakter maskapai dengan reputasi } \\
\text { yang baik }\end{array}$ & .357 & Valid \\
\hline $\begin{array}{l}\text { Batik Air merupakan maskapai yang } \\
\text { memiliki motivasi positif pada penumpang. }\end{array}$ & .282 & Valid \\
\hline $\begin{array}{l}\text { Saya merasa Batik Air mampu membentuk } \\
\text { pengalaman yang bernilai bagi penumpang. }\end{array}$ & .310 & Valid \\
\hline $\begin{array}{l}\text { Saya merasa Batik Air mampu membentuk } \\
\text { keterikatan dengan penumpangnya }\end{array}$ & .398 & Valid \\
\hline
\end{tabular}

Hasil pengolahan data primer

Tabel 3. Hasil Uji Validitas Brand Loyalty Batik Air

\begin{tabular}{cc}
\hline Pertanyaan & $\begin{array}{c}\text { Corrected Item- } \\
\text { Total Correlation }\end{array}$
\end{tabular}

\begin{tabular}{llc}
\hline $\begin{array}{l}\text { Saya memiliki pola pembelian yang } \\
\text { teratur pada Batik Air. }\end{array}$ & .473 & Valid \\
\hline Saya merasa puas dengan Batik Air & .419 & Valid \\
\hline $\begin{array}{l}\text { Saya tidak akan pindah ke maskapai lain } \\
\text { walaupun terdapat faktor penarik yang } \\
\text { cukup kuat }\end{array}$ & .559 & Valid \\
\hline $\begin{array}{l}\text { Saya selalu berusaha bersikap hangat } \\
\text { dengan Batik Air }\end{array}$ & .391 & Valid \\
\hline $\begin{array}{l}\text { Saya merasa maskapai Batik Air mampu } \\
\text { menciptakan kedekatan yang intim dengan } \\
\text { pelanggan }\end{array}$ & .377 & Valid \\
\hline $\begin{array}{l}\text { Saya rela untuk membayar lebih mahal } \\
\text { agar dapat menaiki maskapai Batik Air }\end{array}$ & .317 & Valid \\
\hline $\begin{array}{l}\text { Saya sering secara langsung atau tidak } \\
\text { langsung berinteraksi mengenai Batik Air }\end{array}$ & .406 & Valid \\
\hline $\begin{array}{l}\text { Saya akan berkomitmen untuk terus } \\
\text { menggunakan maskapai Batik Air }\end{array}$ & .377 & Valid \\
\hline
\end{tabular}

Hasil pengolahan data primer

Uji Reliabilitas

Dalam pengujian ini perlu dilakukan menggunakan statistik Cronbanch's Alpha , terdapat dimensi - dimensi yang menyatakan reliabel jika mempunyai angka Cronbanch's Alpha tidak lebih dari 0.6.Tabel dibawah merupakan hasil dari uji reabilitas dari kedua variabel. 
Tabel 4. Hasil Uji Reliabilitas

\begin{tabular}{lccc} 
Variabel & N & Cronbanch's Alpha & Keterangan \\
\hline Brand Trust(X) & 7 & .660 & Reliabel \\
\hline Brand Loyalty (Y) & 8 & .722 & Reliabel
\end{tabular}

\section{Hasil pengolahan data primer}

\section{Uji Hipotesis}

1. Pengujian Hipotesis Pertama (X terhadap Y)

Hasil pengolahan data Brand Trust yaitu variabel bebas terhadap Brand Loyalty yaitu variabel terikat maka dapat dilihat dalam tabel dibawah ini :

Tabel 5. Hasil Koefisien Korelasi (R) Variabel X

\section{Model Summary a}

\begin{tabular}{crrcc}
\hline Model & R & R Square & Adjusted R Square & Std.Error of the Estimate \\
\hline 1 & $.791 \mathrm{a}$ & .625 & .621 & .41426 \\
\hline
\end{tabular}

a.Predictors: (Constant),TRUST

\section{Hasil pengolahan data primer}

Tabel 6. Hasil Uji Test of Significant (Uji t) Variabel X

\begin{tabular}{|c|c|c|c|c|c|c|}
\hline \multirow{2}{*}{\multicolumn{2}{|c|}{ Model }} & \multicolumn{2}{|c|}{$\begin{array}{l}\text { Unstandardize } \\
\text { d Coefficients }\end{array}$} & \multirow{2}{*}{$\begin{array}{c}\begin{array}{c}\text { Standardize } \\
\text { Coeffcients }\end{array} \\
\text { Beta }\end{array}$} & \multirow[t]{2}{*}{$\mathbf{t}$} & \multirow[t]{2}{*}{ Sig } \\
\hline & & B & Std.Error & & & \\
\hline \multirow[t]{2}{*}{1} & (Constant) & .688 & .245 & & 2.806 & .006 \\
\hline & Brand Trust & .812 & .065 & .791 & 12.526 & .000 \\
\hline
\end{tabular}

a. Dependent Variable : LOYALTY

\section{Hasil pengolahan data primer}

Tabel 7. Hasil Uji Varience Fisher (Uji F) Variabel X

\begin{tabular}{lccccc}
\hline Model & Sum of Squares & $\mathbf{d F}$ & Mean Square & $\mathbf{F}$ & Sig. \\
& & & & & \\
\hline 1 Regression & 26.927 & 1 & 26.927 & 156.910 & $.000 \mathrm{~b}$ \\
\hline Residual & 16.131 & 94 & .172 & & \\
\hline Total & 43.058 & 95 & & & \\
\hline a.Dependent Variable :LOYALTY & & & & \\
\hline b.Predictors : (Constant), TRUST & & & & \\
\hline
\end{tabular}

Hasil pengolahan data primer 


\section{Koefisien Korelasi}

Menurut table 4.23, diperoleh kesimpulan bahwa nilai koefisien korelasi (R) untuk variabel independen Brand Trust dengan brand loyalty yaitu sebesar 0,791 Artinya bahwa hubungan antara $\mathrm{X}$ dan $\mathrm{Y}$ dikatakan tinggi Karena berada dalam interval 0,6-0,799, sehingga setiap peningkatan pada variabel brand trust, maka variabel brand loyalty juga akan mengalami peningkatan.

\section{Koefisien Determinasi (R2)}

Menurut table 4.23 didapatkan hasil sebagai koefisien determinasi dengan menggunakan nilai R Square yaitu sebesar 0,625 yang berarti bahwa kemampuan variabel independen Brand Trust (X) dalam menjelaskan variabel dependen Brand Loyalty (Y) adalah sebesar 0,625 sedangkan selebihnya adalah 0,375 diterangkan oleh indikator-indikator yang lain yang tidak dapat dijelaskan dalam model regresi penelitian ini,seperti variabel kepercayaan merek dan kepuasan merek pada pelanggan yang dapat mempengaruhi brand loyalty pelanggan.

\section{Uji Test of Significant (Uji t)}

Menurut table 4.24,didapatkan sebagai hasil uji t untuk variabel independent Brand Trust $(\mathrm{X})$ dengan melihat nilai angka sebesar 12.526 dan signifikan (sig) sebesar 0,000 Artinya Sig. Hitung < 0,05 yaitu $0.00<0,05$. Dengan begitu menunjukkan Ho ditolak dan Ha diterima,bahwa variabel Brand Trust secara individual memiliki pengaruh terhadap Brand Loyalty (Y).

\section{Uji Regresi Sederhana}

$$
\begin{aligned}
& Y=A+B(X) \\
& \text { Brand Loyalty }=0,688+0,812(\text { Brand Trust })
\end{aligned}
$$

Jadi dapat dilihat besar pengaruhnya antara kedua variabel saling berpengaruh dalam membentuk brand loyalty masyarakat dalam menggunakan maskapai penerbangan Batik Air.

\section{Uji Variance Fisher (Uji F)}

Berdasarkan table 4.25 diperoleh uji $\mathrm{F}$ dengan nilai $\mathrm{F}$ sebesar 156.910 dan nilai signifikan (sig) sebesar 0,000.artinya nilai $\mathrm{Sig}<0,05$ yaitu $0.00<0,05$ maka Ho ditolak dan Ha diterima. Dengan begitu menunjukkan bahwa model regresi yang terbentuk sudah fit.

\section{Kesimpulan}

Dengan paparan dan semua hasil uji statistik dan beberapa analisis yang telah dilakukan oleh peneliti dalam penelitian ini ,maka dapat ditemukan kesimpulan sebagai berikut: Berdasarkan hasil uji hipotesis brand trust ( $\mathrm{X}$ ) terhadap brand loyalty (Y), ditemukan bahwa terdapat pengaruh brand trust terhadap brand loyalty maskapai penerbangan Batik Air dengan interval korelasi 0,791dan koefisien determinasi sebesar $62.5 \%$. Berdasarkan hasil penelitian, ditemukan bahwa besar pengaruh brand trust (X) terhadap brand loyalty (Y) penumpang maskapai penerbangan Batik Air adalah sebesar 0.625 yang berarti $62.5 \%$ perubahan pada brand loyalty diakibatkan oleh brand trust. 


\section{Ucapan Terima Kasih}

Ucapan terimakasih ini peneliti sampaikan kepada orang tua, koko, popo dan kepada semua teman-teman yang sudah mendukung dalam penelitian ini. Kemudian juga ucapan terima kasih ini untuk kepada responden yang sudah membantu dalam menjawab setiap pertanyaan dalam penelitian ini.

\section{Daftar Pustaka}

Aaker, A. David. 1997. Manajemen Ekuitas Merek. Alih Bahasa: Aris Ananda, Spektrum Mitra Utama.Jakarta

Azwar, S. (2012). Reliabilitas dan Validitas.Yogyakarta: Pustaka Pelajar Dirgantari,Pratiwi (2018) Gambaran Brand Communication Brand Trust dan Brand Loyalty Pelanggan Kosmetik Sariayu di Indonesia.Jurnal Pendidikan Management Bisnis 3,89-99.Terarsip di https://ejournal.upi.edu/index.php/JBME/article/view/14313/8246

Effendy, Onong Uchjana. (2017). Ilmu Komunikasi, Teori \& Praktik. Bandung: PT. Remaja Rosdakarya. Cetakan ke-28. 9.

Fuz.(2015). Fakta-Fakta Menarik Tentang Batik Air Yang Patut Anda Tahu. 2015 Oktober 26. Traveloka Database.Terarsip di:

https://www.jpnn.com/news/fakta-fakta-menarik-tentang-batik-air-yangpatut-anda-tahu?page $=2$

Kotler dan Keller. (2009). Manajemen Pemasaran. Jilid 1. Edisi ke 13. Jakarta: Erlangga.

Mulyana, Deddy. (2017). Ilmu Komunikasi Suatu Pengantar. Bandung: PT. Remaja Rosdakarya. Cetakan ke-21. 72-73.

Sukendro,Genep.,dan Pandrianto,Nigar (2019).Diagnosa Komunikasi Brand Activation dan Media Digital Atas Eksistensi Brand Studio Rekaman Lokananta.Jurnal Ilmu Komunikasi Untar.Vol 11 No 1.Telah terarsip di : https://journal.untar.ac.id/index.php/komunikasi/article/view/4287/4388 